\title{
Clinical and immunoregulatory effects of roxithromycin therapy for chronic respiratory tract infection
}

\author{
H. Nakamura, S. Fujishima, T. Inoue, Y. Ohkubo, K. Soejima, Y. Waki, M. Mori, T. Urano, \\ F. Sakamaki, S. Tasaka, A. Ishizaka, M. Kanazawa, K. Yamaguchi
}

Clinical and immunoregulatory effects of roxithromycin therapy for chronic respiratory tract infection. H. Nakamura, S. Fujishima, T. Inoue, Y. Ohkubo, K. Soejima, Y. Waki, M. Mori, T. Urano, F. Sakamaki, S. Tasaka, A. Ishizaka, M. Kanazawa, K. Yamaguchi. (C)ERS Journals Ltd 1999.

ABSTRACT: The clinical and immunoregulatory effects of long-term macrolide antibiotic therapy for patients with chronic lower respiratory tract infections (CLRTI) were investigated.

Clinical parameters and neutrophil chemotactic mediators in the epithelial lining fluid (ELF) of CLRTI patients $(n=10)$ were examined before and after 3 months oral administration of roxithromycin (RXM). The in vitro effects of RXM were also examined on the release of these mediators from alveolar macrophages (AM) and neutrophils.

Arterial oxygen tension $(p<0.05)$, vital capacity $(\mathrm{VC})(\mathrm{p}<0.001), \% \mathrm{VC}(\mathrm{p}<0.05)$ and forced expiratory volume in one second $(p<0.01)$ were improved after RXM treatment, but airway bacteria were not eradicated. Among the mediators, the levels of interleukin (IL)-8, neutrophil elastase (NE) and leukotriene $B_{4}\left(\mathrm{LTB}_{4}\right)$ were higher in ELF than in plasma of CLRTI patients and they decreased after RXM treatment $(\mathrm{n}=7, \mathrm{p}<0.05$ for each). $\mathrm{RXM}$ concentrations were significantly increased in the bronchoalveolar lavage cells of the treated patients. In in vitro experiments, RXM showed inhibitory effects on IL-8 release from AM and neutrophils.

In conclusion, interleukin-8, neutrophil elastase and leukotriene $B_{4}$ contribute to the neutrophilic inflammation in the airways of chronic lower respiratory tract infection patients and the clinical effects of roxithromycin may, in part, be attributable to the suppression of excess release of the chemotactic mediators from inflammatory cells.

Eur Respir J 1999; 13: 1371-1379.
Dept of Medicine, School of Medicine, Keio University, Tokyo, Japan.

Correspondence: S. Fujishima

Dept of Emergency and Critical Care Medicine

School of Medicine

Keio University

35 Shinanomachi

Shinjuku-ku

Tokyo 160

Japan

Fax: 81332251320

Keywords: Chronic lower respiratory tract infections

interleukin-8

leukotriene $\mathrm{B}_{4}$

neutrophil elastase

roxithromycin

Received: February 61998

Accepted after revision February 11999

This study was supported, in part, by a Grant-in-Aid from the Japanese Ministry of Education, Science, and Culture, the Keio Fukuzawa Fund, and the Keio University Medical Science Fund.
The clinical effectiveness of long-term macrolide antibiotic therapy has recently been reported in patients with diffuse panbronchiolitis (DPB) [1-3]. Before the introduction of macrolide therapy, DPB was a chronically progressive disease which resulted in chronic respiratory failure. DPB is characterized by chronic inflammation of the respiratory bronchioles and parabronchial and luminal infiltration of inflammatory cells, and is associated with continuous airway infection especially Pseudomonas aeruginosa $[1,2]$. This disease is prevalent mainly in Japan, but was recently reported in the USA [4]. Similar airway inflammation, namely chronic lower respiratory tract infections (CLRTI), is also observed in patients with bronchiectasis (BE). Previous studies have suggested that this effect cannot be ascribed to its antibacterial action [3, 5] but rather, its immunoregulatory function, such as inhibition of neutrophil chemotaxis and superoxide production in vitro $[5,6]$. An in vivo study suggested that macrolide treatment induced a decrease in the neutrophil chemotactic activities of bronchoalveolar lavage (BAL) fluid from patients with DPB [2]. However, the precise mechanisms responsible for this clinical efficacy remain unclear.
Neutrophil accumulation is a defining feature of airway inflammation in patients with CLRTI including DPB and $\mathrm{BE}[1,2]$. Although neutrophils are important effector cells against bacterial infections, neutrophil-derived oxygen metabolites and proteolytic enzymes could have harmful effects on lung tissues and may exacerbate clinical symptoms $[1,7]$. Various mediators including interleukin (IL)-8, IL-1 $\beta$, leukotriene (LT)B $\mathrm{B}_{4}$ and neutrophil elastase (NE) may be involved in the recruitment and activation of neutrophils in patients with airway infections including CLRTI and cystic fibrosis [7-10]. Previous reports have indicated complex interactions between these mediators both in vivo and in vitro. For example, IL8 is induced by IL-1 $\beta$ in various cells [11-13]. LTB $_{4}$ upregulates neutrophil-derived IL-8 [14]. IL-8 correlates with NE in the airways of CLRTI patients [7], and NE from patients with cystic fibrosis induces IL-8 gene expression in epithelial cells [15]. Thus, it is reasonable to speculate that the combination of these mediators synergistically induces airway inflammation. However, precise roles of these mediators in the pathogenesis of CLRTI have not been fully elucidated. Therefore, the neutrophil chemotactic mediators IL-8, IL-1 $\beta$, tumour necrosis 
factor (TNF)- $\alpha, \mathrm{LTB}_{4}, \mathrm{NE}$ and $\mathrm{C} 5 \mathrm{a}$ were investigated in CLRTI patients.

In this study, it was hypothesized that macrolide antibiotics decrease the release of neutrophil chemotactic mediators from inflammatory cells, which results in clinical improvement. To prove this hypothesis, roxithromycin (RXM), a new macrolide with enhanced stability in gastric juice and a prolonged half-life [16], was administered to patients with CLRTI including DPB and BE, and the clinical symptoms, chest radiographic findings, pulmonary functions and sputum culture were examined. The concentrations of IL- 8, IL- $1 \beta$, TNF- $\alpha$, LTB $_{4}$, NE and C5a were measured in BAL fluid from the CLRTI patients before and after the treatment with RXM. Intracellular RXM concentrations in BAL cells, plasma and BAL supernatant were then measured, and the effects of RXM on the release of these chemotactic mediators from alveolar macrophages (AM) and neutrophils in culture investigated.

\section{Patients and methods}

\section{Subjects}

Ten patients with CLRTI, who had complained of chronic purulent sputum for at least 6 months, and whose chest radiographs suggested bronchiolitis and/or BE were studied. Seven patients were diagnosed as DPB on the basis of the clinical diagnostic criteria published by the Japanese Ministry of Health and Welfare [2]. The remaining three patients were identified as having BE by computed tomography (CT) scan, which revealed bronchial dilatation without diffuse granular shadows. All patients had accompanying chronic sinusitis. Their average age (mean \pm SEM) was $51.8 \pm 5.5 \mathrm{yrs}$, and none of the patients had ever smoked. No patient had prior treatment with glucocorticoids or long-term macrolides. Three control subjects were asymptomatic and had normal chest radiographic findings. Their average age was $45.3 \pm 6.7 \mathrm{yrs}$. Two were nonsmokers and the other was a smoker. Informed consent was obtained from all of the patients and control subjects.

\section{Treatment and examination schedule}

CLRTI patients were treated with RXM $150 \mathrm{mg}$ b.i.d. for 3 months. No other antibiotics or glucocorticoids were administered during the period. Clinical symptoms were recorded by a pulmonologist in the outpatient clinic every
2 weeks. Clinical improvement after the 3 -month treatment period was evaluated by three other pulmonologists who were not involved in this study. Based on physical examination and subjective findings, clinical symptoms were classified according to the criteria described in table 1 . BAL, blood tests, pulmonary function tests, chest radiography and sputum culture were performed before and after the treatment. Improvement of the chest radiographic findings was assessed by three pulmonologists in a blinded manner. Briefly, three or four chest radiographs of each CLRTI patient, which were taken at different time points and randomly arranged, were evaluated without identification of the patient name and the examination date. The chest radiographic findings were classified according to the criteria described in table 1. Chest CT scans were also performed in all of the CLRTI patients to confirm the diagnosis. BE with peribronchial infiltration was demonstrated in all CLRTI patients when BE was defined as having dilated bronchi greater than the accompanying artery on the CT scans. Diffuse granular shadows with a centrilobular pattern were observed in DPB patients on the CT scans.

\section{Bronchoalveolar lavage}

BAL was performed using a previously described standard protocol [17, 18]. In brief, a bronchoscope was wedged into a segment of the right middle lobe or lingula in which inflammatory findings were observed on a chest radiograph or CT scan. Sterile normal saline at room temperature was instilled through the bronchoscope in $50-\mathrm{mL}$ volumes to a total of $150 \mathrm{~mL}$. The recovered BAL fluid was filtered through sterile gauze, and the cells were counted. Cytospin preparations were made for cell differential counts. The fluid was centrifuged at $200 \times g$ for 5 min, and the supernatant was collected. No significant adverse effects were observed after the procedure.

\section{Quantification of neutrophil chemotactic mediators}

Concentrations of neutrophil chemotactic mediators in BAL fluid and plasma of CLRTI patients and control subjects were determined as follows. IL-8 (Genentech Inc., San Francisco, CA, USA), TNF- $\alpha$ (Otsuka, Tokushima, Japan) and NE (E. Merck, Darmstadt, Germany) levels were measured with a sandwich enzyme-linked immunosorbent assay (ELISA). LTB 4 (Amersham, Buckinghamshire, UK), IL-1 $\beta$ (Amersham) and C5a (Medgenix Diagnostics S.A., Brussels, Belgium) levels were measured

Table 1. - Assessment of clinical symptoms and chest radiographic findings

\begin{tabular}{|c|c|c|c|c|c|c|c|}
\hline \multirow[b]{2}{*}{ Score } & \multicolumn{5}{|c|}{ Clinical symptoms } & \multicolumn{2}{|c|}{ Chest radiographic findings } \\
\hline & Cough & Sputum & Wheeze & Dyspnoea & Sinusitis & $\begin{array}{l}\text { Diffuse granular } \\
\text { shadow }\end{array}$ & $\begin{array}{l}\text { Peribronchial } \\
\text { infiltrates }\end{array}$ \\
\hline 3 & Persistent & $\begin{array}{l}\text { Purulent } \\
\quad \geq 10 \text { times } \cdot \mathrm{day}^{-1}\end{array}$ & $\begin{array}{l}\text { Diffuse } \\
\text { severe }\end{array}$ & At rest & $\begin{array}{l}\text { Severe purulent } \\
\text { discharge }\end{array}$ & Severe & Severe \\
\hline 2 & Frequent & $\begin{array}{l}\text { Purulent } \\
\quad<10 \text { times } \cdot \text { day }^{-1}\end{array}$ & $\begin{array}{l}\text { Diffuse } \\
\text { mild }\end{array}$ & $\begin{array}{l}\text { On mild } \\
\text { exertion }\end{array}$ & $\begin{array}{l}\text { Mild purulent } \\
\text { discharge }\end{array}$ & Moderate & Moderate \\
\hline 1 & Occasional & Serous & $\begin{array}{l}\text { Localized } \\
\text { mild }\end{array}$ & $\begin{array}{l}\text { On moderate } \\
\text { exertion }\end{array}$ & Serous discharge & Mild & Mild \\
\hline 0 & None & None & None & None & None & None & None \\
\hline
\end{tabular}


using a radioimmunoassay (RIA). Epithelial lining fluid (ELF) concentrations of these mediators were calculated using a BAL fluid to plasma ratio of urea nitrogen [19].

\section{Quantification of roxithromycin concentrations}

RXM concentrations in plasma, BAL supernatant and BAL cells were determined by disc method using Micrococcus luteus American Type Culture Collection (ATCC; Rockville, MD, USA) 9341 [20]. BAL was performed 16 $\mathrm{h}$ after the final ingestion of RXM. Blood was drawn $12 \mathrm{~h}$ after the intake. BAL cells were frozen at $-70^{\circ} \mathrm{C}$ for $1 \mathrm{~h}$ and thawed at $37^{\circ} \mathrm{C}$ for $1 \mathrm{~h}$. These procedures were repeated three times, and intracellular RXM was extracted [21]. Intracellular RXM concentrations of BAL cells were calculated using $2,491 \mu^{3}$ as the volume of a macrophage [22]. Neutrophil volume was not considered for this calculation because the total volume in BAL cells is much smaller and its life span is much shorter than a macrophage.

In vitro cytokine production and release from alveolar macrophages and neutrophils

BAL cells containing $>90 \%$ AM from four control subjects were used to examine the potential of AM to produce and release cytokines. The cells were divided into four groups and each group was preincubated with RPMI1640 containing either $0,0.5,5$ or $50 \mu \mathrm{g} \cdot \mathrm{mL}^{-1}$ of RXM for $30 \mathrm{~min}$. Then, $1 \mu \mathrm{g} \cdot \mathrm{mL}^{-1}$ of lipopolysaccharide (LPS; Escherichia coli 055: B5; Difco, Detroit, MI, USA) was added and the cells were cultured for $4 \mathrm{~h}$. To quantify cellassociated IL-8, the cells were lysed, and cell-associated IL-8, and extracellular IL- 8 and TNF- $\alpha$ were measured by ELISA, and extracellular IL- $1 \beta$ was measured by RIA, as described above. Peripheral blood neutrophils were separated by a density gradient centrifugation from seven healthy volunteers. Neutrophil purity was $>98 \%$. The preincubation and culture procedures were the same as those for AM except that extracellular TNF- $\alpha$ and IL- $1 \beta$ were not measured.

\section{Statistical analysis}

All data are presented as mean \pm SEM. Unpaired Student's t-test and analysis of variance (ANOVA) were used to compare mean values. To analyse the relationship between paired values, paired Student's t-test or Wilcoxon test was used based on the distribution of the data. Simple regression analysis was performed to evaluate correlation among neutrophil counts and mediator concentrations in ELF. Significance was accepted at $\mathrm{p}<0.05$.

\section{Results}

\section{Clinical results}

Table 2 represents clinical symptoms during treatment with RXM in CLRTI patients. CLRTI patients showed improvement of clinical symptoms based on the total scores $(p<0.0001)$, but the percentage of improvement varied in each patient. Most of the clinical symptoms were improved four weeks after initiating treatment with RXM. Total symptom scores were higher in DPB $(n=7)$ than in $\mathrm{BE}(\mathrm{n}=3)$ before treatment $(11.6 \pm 0.6$ versus $7.7 \pm$ $1.2, \mathrm{p}<0.01)$. The total scores decreased with 12 weeks of treatment in DPB $(\mathrm{p}<0.001)$. There was no difference in the percentage of improvement between DPB and BE $(60.1 \pm 7.2$ versus $59.0 \pm 5.9 \%)$.

Table 3 shows chest radiographic findings and sputum culture before and after treatment with RXM. Improvement of the total scores on chest radiographs was observed in all CLRTI patients $(\mathrm{p}<0.001)$, but the degree of the improvement differed in each patient. Total chest radiographic scores were higher in DPB $(n=7)$ than in BE $(\mathrm{n}=3)$ before treatment $(4.6 \pm 0.2$ versus $2.0 \pm 0.6, \mathrm{p}<0.001)$. The total scores decreased with 12 weeks of treatment in DPB $(p<0.01)$. There was no difference in the percentage of improvement between DPB and BE (61.4 \pm 9.7 versus $72.3 \pm 14.7 \%$ ). Sputum bacteria were cultured in blood agar, chocolate agar, Conradi-Drigalski agar, and Sabouraud agar media for $48 \mathrm{~h}$ and the numbers of bacteria were classified as: $3+,>500$ colonies; $2+, 200-500$ colonies; 1+, 1-199 colonies; or ND (not detected). Purulent sputum was obtained from all 10 patients, although no bacteria were detected in two patients (cases 7 and 8). Although the number of bacteria decreased in three patients including two with alteration of bacteria (cases 6 and 9), bacterial eradication was not observed in any of the patients.

Table 2. - Changes in clinical symptoms during treatment with roxithromycin in patients with chronic lower respiratory tract infections

\begin{tabular}{|c|c|c|c|c|c|c|c|c|c|c|c|c|c|c|c|c|c|c|c|c|}
\hline \multirow[t]{2}{*}{ Case } & \multirow[t]{2}{*}{ Diagnosis } & \multicolumn{3}{|c|}{ Cough } & \multicolumn{3}{|c|}{ Sputum } & \multicolumn{3}{|c|}{ Wheeze } & \multicolumn{3}{|c|}{ Dyspnoea } & \multicolumn{3}{|c|}{ Sinusitis } & \multicolumn{3}{|c|}{ Total } & \multirow{2}{*}{$\underset{\%}{\text { Impr. }}$} \\
\hline & & 0W & $4 \mathrm{~W}$ & $12 \mathrm{~W}$ & $0 \mathrm{~W}$ & $4 \mathrm{~W}$ & $12 \mathrm{~W}$ & $0 \mathrm{~W}$ & $4 \mathrm{~W}$ & $12 \mathrm{~W}$ & $0 \mathrm{~W}$ & $4 \mathrm{~W}$ & $12 \mathrm{~W}$ & $0 \mathrm{~W}$ & $4 \mathrm{~W}$ & $12 \mathrm{~W}$ & 0W & $4 \mathrm{~W}$ & $12 \mathrm{~W}$ & \\
\hline 1 & $\mathrm{BE}$ & 2 & 1 & 1 & 2 & 1 & 1 & 0 & 0 & 0 & 0 & 0 & 0 & 2 & 1 & 1 & 6 & 3 & 3 & 50 \\
\hline 2 & DPB & 2 & 1 & 1 & 3 & 2 & 1 & 3 & 2 & 2 & 3 & 2 & 1 & 3 & 2 & 2 & 14 & 9 & 7 & 50 \\
\hline 3 & DPB & 3 & 1 & 1 & 3 & 2 & 1 & 2 & 1 & 0 & 2 & 1 & 1 & 2 & 1 & 1 & 12 & 6 & 4 & 67 \\
\hline 4 & DPB & 2 & 0 & 0 & 3 & 1 & 1 & 2 & 1 & 1 & 3 & 1 & 1 & 3 & 1 & 1 & 13 & 4 & 4 & 69 \\
\hline 5 & DPB & 2 & 1 & 0 & 3 & 2 & 1 & 2 & 2 & 1 & 2 & 1 & 1 & 2 & 1 & 1 & 11 & 7 & 4 & 64 \\
\hline 6 & $\mathrm{BE}$ & 2 & 1 & 1 & 2 & 1 & 1 & 2 & 0 & 0 & 2 & 0 & 0 & 2 & 1 & 1 & 10 & 3 & 3 & 70 \\
\hline 7 & $\mathrm{BE}$ & 2 & 1 & 1 & 3 & 1 & 1 & 0 & 0 & 0 & 0 & 0 & 0 & 2 & 1 & 1 & 7 & 3 & 3 & 57 \\
\hline 8 & DPB & 2 & 1 & 1 & 2 & 1 & 1 & 2 & 1 & 2 & 2 & 2 & 2 & 2 & 1 & 1 & 10 & 6 & 7 & 30 \\
\hline 9 & DPB & 2 & 0 & 0 & 3 & 1 & 0 & 2 & 0 & 0 & 2 & 0 & 0 & 2 & 1 & 1 & 11 & 2 & 1 & 91 \\
\hline 10 & DPB & 2 & 1 & 1 & 2 & 1 & 1 & 2 & 1 & 1 & 2 & 1 & 1 & 2 & 1 & 1 & 10 & 5 & 5 & 50 \\
\hline Mean & & 2.1 & 0.8 & 0.7 & 2.6 & 1.3 & 0.9 & 1.7 & 0.8 & 0.7 & 1.8 & 0.8 & 0.7 & 2.2 & 1.1 & 1.1 & 10.4 & 4.8 & 4.1 & 61 \\
\hline
\end{tabular}

W: weeks; Impr.: improvement; BE: bronchiectasis; DPB: diffuse panbronchiolitis. 
Table 3. - Changes in chest radiograph and bacteriological findings before and after treatment with roxithromycin in chronic lower respiratory tract infections

\begin{tabular}{|c|c|c|c|c|c|c|c|c|c|c|}
\hline \multirow[t]{3}{*}{ Case } & \multirow[t]{3}{*}{ Diag. } & \multicolumn{6}{|c|}{ Chest radiograph } & \multirow{3}{*}{$\begin{array}{c}\text { Improvement } \\
\%\end{array}$} & \multirow{2}{*}{\multicolumn{2}{|c|}{ Sputum culture }} \\
\hline & & \multicolumn{2}{|c|}{$\begin{array}{l}\text { Diffuse granular } \\
\text { shadow }\end{array}$} & \multicolumn{2}{|c|}{$\begin{array}{l}\text { Peribronchial } \\
\text { infiltrates }\end{array}$} & \multicolumn{2}{|c|}{ Total } & & & \\
\hline & & Before & After & Before & After & Before & After & & Before & After \\
\hline 1 & $\mathrm{BE}$ & 0 & 0 & 1 & 0 & 1 & 0 & 100 & $\begin{array}{c}\text { Pneumococcus } \\
1+\end{array}$ & $\begin{array}{c}\text { H. influenzae } \\
2+\end{array}$ \\
\hline 2 & DPB & 3 & 1 & 2 & 1 & 5 & 2 & 60 & P. aeruginosa & $\begin{array}{l}\text { P. aeruginosa } \\
3+\end{array}$ \\
\hline 3 & DPB & 2 & 1 & 2 & 1 & 4 & 2 & 50 & $\begin{array}{c}\text { H. parahaemolyticus } \\
1+\end{array}$ & $\begin{array}{c}\text { H. influenzae } \\
2+\end{array}$ \\
\hline 4 & DPB & 3 & 0 & 2 & 0 & 5 & 0 & 100 & $\begin{array}{c}\text { Pneuтососсиs } \\
3+\end{array}$ & $\begin{array}{c}\text { H. influenzae } \\
3+\end{array}$ \\
\hline 5 & DPB & 3 & 2 & 2 & 1 & 5 & 3 & 40 & $\begin{array}{c}P . \text { aeruginosa } \\
3+\end{array}$ & $\begin{array}{c}\text { P. aeruginosa } \\
3+\end{array}$ \\
\hline 6 & $\mathrm{BE}$ & 1 & 0 & 2 & 1 & 3 & 1 & 67 & $\begin{array}{c}\text { H. influenzae } \\
2+\end{array}$ & $\begin{array}{c}\text { H. parahaemolyticus } \\
1+\end{array}$ \\
\hline 7 & $\mathrm{BE}$ & 0 & 0 & 2 & 1 & 2 & 1 & 50 & ND & ND \\
\hline 8 & DPB & 2 & 2 & 2 & 1 & 4 & 3 & 25 & ND & ND \\
\hline 9 & DPB & 3 & 1 & 2 & 0 & 5 & 1 & 80 & $\begin{array}{c}\text { H. influenzae } \\
3+\end{array}$ & $\begin{array}{c}\text { Pneumococcus } \\
1+\end{array}$ \\
\hline 10 & DPB & 3 & 1 & 1 & 0 & 4 & 1 & 75 & $\begin{array}{c}\text { Pneumococcus } \\
3+\end{array}$ & $\begin{array}{c}\text { Pneumococcus } \\
2+\end{array}$ \\
\hline Mean & & 2.0 & 0.8 & 1.8 & 0.6 & 3.8 & 1.4 & 65 & & \\
\hline
\end{tabular}

Diag.: diagnosis; BE: bronchiectasis; DPB: diffuse panbronchiolitis. H. influenzae: Haemophilus influenzae; P. aeruginosa: Pseudomonas aeruginosa; H. parahaemolyticus: Haemophilus parahaemolyticus. Sputum culture, $3+:>500$ colonies; 2+: 200-500 colonies; 1+: 1-199 colonies; ND: not detected.

The results of arterial blood gas analysis and pulmonary function tests are shown in table 4. Arterial oxygen tension $\left(\mathrm{Pa}, \mathrm{O}_{2}\right)$, vital capacity $(\mathrm{VC}), \% \mathrm{VC}$ and forced expiratory volume in one second (FEV1) were significantly improved in patients with CLRTI after treatment with RXM. C-reactive protein $\left(2.38 \pm 0.85 \mathrm{mg} \cdot \mathrm{dL}^{-1}\right.$ versus $0.56 \pm 0.25$ $\left.\mathrm{mg} \cdot \mathrm{dL}^{-1}, \mathrm{p}<0.05, \mathrm{n}=9\right)$ and erythrocyte sedimentation rate $\left(54.2 \pm 11.5 \mathrm{~mm} \cdot \mathrm{h}^{-1}\right.$ versus $33.7 \pm 13.3 \mathrm{~mm} \cdot \mathrm{h}^{-1}, \mathrm{p}<0.001, \mathrm{n}=$ 9) were decreased after treatment with RXM. Peripheral white blood cell counts did not change significantly $\left(8,122 \pm 1,016\right.$ cells $\cdot \mathrm{mm}^{-3}$ versus $6,244 \pm 566$ cells $\cdot \mathrm{mm}^{-3}$, $\mathrm{p}=0.08, \mathrm{n}=9$ ). Arterial blood gas analysis and pulmonary function tests were not performed in two patients, and blood testing was not carried out in one patient after treatment with RXM due to the inconvenience for the patients.

Table 4. - Changes in pulmonary functions in patients with chronic lower respiratory tract infections

\begin{tabular}{lcl}
\hline & $\begin{array}{c}\text { Before treatment } \\
\text { with RXM } \\
(\mathrm{n}=8)\end{array}$ & $\begin{array}{c}\text { After treatment } \\
\text { with RXM } \\
(\mathrm{n}=8)\end{array}$ \\
\hline${\mathrm{Pa}, \mathrm{O}_{2} \text { Torr }}_{\mathrm{a}_{\mathrm{CO}} \text { Torr }}$ & $66.9 \pm 4.4$ & $84.0 \pm 6.4^{*}$ \\
$\mathrm{VC} \mathrm{L}$ & $39.6 \pm 2.0$ & $40.9 \pm 1.9$ \\
$\% \mathrm{VC}$ & $2.42 \pm 0.38$ & $2.86 \pm 0.36^{* * *}$ \\
$\mathrm{FEV} 1 \mathrm{~L}$ & $71.6 \pm 6.7$ & $90.8 \pm 7.5^{*}$ \\
$\mathrm{FEV} 1 \%$ & $1.69 \pm 0.31$ & $2.01 \pm 0.31^{* *}$ \\
\hline
\end{tabular}

Values are presented as mean \pm SEM. RXM: roxithromycin; $P \mathrm{a}, \mathrm{O}_{2}$ : arterial oxygen tension; $\mathrm{Pa}_{2} \mathrm{CO}_{2}$ : arterial carbon dioxide tension; VC: vital capacity; FEV1: forced expiratory volume in one second. $*$ : $\mathrm{p}<0.05 ; * *$ : $\mathrm{p}<0.01 ; * * *$ : $\mathrm{p}<0.001$, compared with the value before treatment with RXM. (1 Torr $=0.133 \mathrm{kPa}$.)
Bronchoalveolar lavage cells and chemotactic mediators in plasma and bronchoalveolar lavage fluid of untreated patients

BAL cell counts and differentials before and after RXM treatment are shown in table 5. BAL was performed in all 10 CLRTI patients before treatment and in seven patients after RXM treatment. Three patients did not agree to the second bronchoscopy. The percentage of neutrophils was increased in CLRTI patients compared with that in the control subjects before treatment $(\mathrm{p}<0.05)$. After treatment with RXM, total cell, lymphocyte, and neutrophil counts were significantly decreased $(\mathrm{p}<0.05$, for each by Wilcoxon test). The decrease in total cell and neutrophil counts was also significant in DPB $(n=5)(p<0.05$ for both). The percentage of macrophages increased and that of neutrophils decreased after treatment in DPB $(\mathrm{p}<0.05$ for both) as well as in all CLRTI patients. The percentage of neutrophils was higher in untreated DPB $(n=5)$ than in control subjects $(\mathrm{p}<0.0001)$. Total cell counts, neutrophil counts and percentage before treatment in $\operatorname{BE}(n=3)$ were $97.3 \pm 57.9 \times 10^{6}$ cells $\cdot \mathrm{mL} \mathrm{ELF}^{-1}, 69.3 \pm 60.2 \times 10^{6}$ cells . $\mathrm{mL} \mathrm{ELF}^{-1}$, and $46.4 \pm 22.3 \%$, respectively.

Pretreatment levels of neutrophil chemotactic mediators in ELF and plasma are shown in table 6. IL-8 concentrations in the ELF of CLRTI patients were higher than those of control subjects $(\mathrm{p}<0.05)$. IL-8, IL-1 $\beta$, NE and $\mathrm{LTB}_{4}$ concentrations in the ELF from CLRTI patients were increased compared with plasma concentrations $(\mathrm{n}=8, \mathrm{p}<0.01, \mathrm{p}<0.01, \mathrm{p}<0.05$ and $\mathrm{p}<0.05$, respectively). The mediator concentrations in ELF were compared between DPB $(n=7)$ and BE $(n=3)$. IL-8 levels were lower in DPB than in BE $\left(34.1 \pm 8.5\right.$ versus $88.2 \pm 19.4 \mathrm{ng} \cdot \mathrm{mL}^{-1}$, $\mathrm{p}<0.05)$ and were higher in both DPB and BE than in 
Table 5. - Bronchoalveolar lavage cell counts and differentials before and after treatment with roxithromycin

\begin{tabular}{|c|c|c|c|}
\hline & \multicolumn{2}{|c|}{ Patients with CLRTI $(n=7)$} & \multirow{2}{*}{$\begin{array}{c}\text { Control subjects } \\
\qquad(\mathrm{n}=3)\end{array}$} \\
\hline & Before treatment & After treatment & \\
\hline $\begin{array}{l}\text { Total cell count } \\
\times 10^{6} \cdot \mathrm{mL} \mathrm{ELF}^{-1}\end{array}$ & $\begin{array}{l}81.7 \pm 32.6 \\
(45.8)\end{array}$ & $\begin{array}{r}13.8 \pm 5.3 \\
(11.2)^{*}\end{array}$ & $3.7 \pm 1.4$ \\
\hline $\begin{array}{l}\text { Macrophage count } \\
\times 10^{6} \cdot \mathrm{mL} \mathrm{ELF}^{-1}\end{array}$ & $\begin{array}{c}10.2 \pm 4.1 \\
(5.9)\end{array}$ & $\begin{array}{c}4.0 \pm 1.2 \\
(4.0)\end{array}$ & $3.4 \pm 1.3$ \\
\hline$\%$ Macrophage & $19.2 \pm 8.5^{* * *}$ & $48.0 \pm 13.9^{*}$ & $92.0 \pm 0.7$ \\
\hline $\begin{array}{l}\text { Lymphocyte count } \\
\times 10^{6} \cdot \mathrm{mL} \mathrm{ELF}^{-1}\end{array}$ & $\begin{array}{l}3.1 \pm 1.0 \\
(2.0)\end{array}$ & $\begin{array}{c}0.6 \pm 0.2 \\
(0.9)^{*}\end{array}$ & $0.3 \pm 0.1$ \\
\hline \% Lymphocyte & $6.9 \pm 3.0$ & $7.1 \pm 2.6$ & $7.7 \pm 0.4$ \\
\hline $\begin{array}{l}\text { Neutrophil count } \\
\times 10^{6} \cdot \mathrm{mL} \mathrm{ELF}^{-1}\end{array}$ & $\begin{array}{c}68.5 \pm 31.8 \\
(34.0)\end{array}$ & $\begin{array}{c}9.2 \pm 5.8 \\
(2.6)^{*}\end{array}$ & $0.02 \pm 0.02$ \\
\hline$\%$ Neutrophil & $73.9 \pm 11.0 * *$ & $44.8 \pm 14.8 *$ & $0.3 \pm 0.3$ \\
\hline
\end{tabular}

Values are presented as mean \pm SEM with median values in parentheses. CLRTI: chronic lower respiratory tract infections; ELF: epithelial lining fluid. $* *: \mathrm{p}<0.01 ; * * *: \mathrm{p}<0.001$, compared with control subjects; $*: \mathrm{p}<0.05$, compared with the value before treatment.

control subjects $(\mathrm{p}<0.05$ for both). There were no significant differences in ELF concentrations of TNF- $\alpha$, IL$1 \beta, \mathrm{NE}, \mathrm{LTB}_{4}$ and $\mathrm{C} 5 \mathrm{a}$ between DPB and BE $(0.16 \pm 0.07$ versus $0 \pm 0 \mathrm{ng} \cdot \mathrm{mL}^{-1}, 4.95 \pm 1.50$ versus $9.01 \pm 1.07 \mathrm{ng} \cdot \mathrm{mL}^{-1}$, $75.1 \pm 39.2$ versus $171.3 \pm 59.7 \mu \mathrm{g} \cdot \mathrm{mL}^{-1}, 4.31 \pm 1.64$ versus $3.14 \pm 1.66 \mathrm{ng} \cdot \mathrm{mL}^{-1}, 360 \pm 188$ versus $267 \pm 267 \mathrm{ng} \cdot \mathrm{mL}^{-1}$, respectively).

Roxithromycin concentrations in plasma, epithelial lining fluid and bronchoalveolar lavage cells

After three months of administration, RXM concentrations in plasma, BAL supernatants and BAL cells were measured in CLRTI patients. As shown in table 7, intracellular RXM concentrations in AM were markedly increased compared with those in plasma and ELF ( $\mathrm{p}<$ 0.001 ), but ELF concentrations were similar to those in plasma.

Comparison of epithelial lining fluid mediators before and after the treatment with roxithromycin

As shown in figure 1, the ELF levels of IL-8 (60.9 \pm 13.8 versus $\left.17.3 \pm 40 \mathrm{ng} \cdot \mathrm{mL}^{-1}, \mathrm{p}<0.05\right), \mathrm{NE}(125.5 \pm 47.5$ versus $\left.16.8 \pm 7.1 \mu \mathrm{g} \cdot \mathrm{mL}^{-1}, \mathrm{p}<0.05\right)$ and $\mathrm{LTB}_{4}(4.80 \pm 1.48$ versus $\left.1.57 \pm 0.54 \mathrm{ng} \cdot \mathrm{mL}^{-1}, \mathrm{p}<0.05\right)$ were significantly decreased after the treatment with RXM $(n=7)$. The ELF levels of IL-1 $\beta\left(6.42 \pm 1.54\right.$ versus $\left.4.27 \pm 1.01 \mathrm{ng} \cdot \mathrm{mL}^{-1}\right)$, TNF- $\alpha$ $\left(0.12 \pm 0.07\right.$ versus $\left.0.05 \pm 0.04 \mathrm{ng} \cdot \mathrm{mL}^{-1}\right)$ and $\mathrm{C5a}(394 \pm 197$ versus $125 \pm 77 \mathrm{ng} \cdot \mathrm{mL}^{-1}$ ) did not change after treatment $(\mathrm{n}=7)$.

\section{Correlation between neutrophil count and mediator con- centrations}

The ELF concentrations of IL-8, NE and C5a correlated with neutrophil counts before treatment with RXM in 10 CLRTI patients $(\mathrm{r}=0.642, \mathrm{p}<0.05 ; \mathrm{r}=0.845, \mathrm{p}<0.01 ; \mathrm{r}=$ $0.845, \mathrm{p}<0.01$, respectively) but this was only due to two outliers. TNF- $\alpha$, IL- $1 \beta$, and $\mathrm{LTB}_{4}$ concentrations did not correlate with the neutrophil counts. There was a significant correlation between IL-8 and either NE ( $\mathrm{r}=0.837$, $\mathrm{p}<0.01)$ or IL-1 $\beta(\mathrm{r}=0.670, \mathrm{p}<0.05)$. However, C5a, LTB 4 , nor TNF- $\alpha$ correlated with IL-8. In addition, NE correlated with C5a or IL-1 $\beta$, $(r=0.770, p<0.01 ; r=0.650, p<0.05$, respectively). There were no significant correlations between any other combinations of the mediators before treatment with RXM in CLRTI patients.

Effects of roxithromycin on interleukin-8, tumour necrosis factor- $\alpha$ and interleukin- $1 \beta$ release from alveolar macrophages

The low concentration of RXM $\left(0.5 \mu \mathrm{g} \cdot \mathrm{mL}^{-1}\right)$ increased extracellular and total IL-8 from AM, while the high concentration of RXM $\left(50 \mu \mathrm{g} \cdot \mathrm{mL}^{-1}\right)$ decreased the release of IL-8 and increased the amount of intracellular IL-8 (fig. $2 a)$. Figure $2 b$ indicated decreased release of IL- 8 from neutrophils at the high RXM concentration. These observations suggested that the high concentration of RXM inhibited the release, but not the production, of IL-8 in AM and neutrophils. RXM $\left(50 \mu \mathrm{g} \cdot \mathrm{mL}^{-1}\right)$ decreased extracellular release of TNF- $\alpha$ from AM (fig. 3a), while there were no significant effects of RXM on the release of IL$1 \beta$ (fig. 3b).

Table 6. - Neutrophil chemotactic mediator concentrations in epithelial lining fluid (ELF) and plasma from patients with chronic lower respiratory tract infections (CLRTI) and control subjects

\begin{tabular}{|c|c|c|c|c|c|c|}
\hline & $\begin{array}{c}\text { IL-8 } \\
\mathrm{ng} \cdot \mathrm{mL}^{-1}\end{array}$ & $\begin{array}{c}\mathrm{TNF}-\alpha \\
\mathrm{ng} \cdot \mathrm{mL}^{-1}\end{array}$ & $\underset{\mathrm{ng} \cdot \mathrm{mL}^{-1}}{\mathrm{IL}}$ & $\begin{array}{c}\mathrm{NE} \\
\mu \mathrm{g} \cdot \mathrm{mL}^{-1}\end{array}$ & $\underset{\mathrm{ng} \cdot \mathrm{mL}^{-1}}{\mathrm{LTB}_{4}}$ & $\underset{\mathrm{ng} \cdot \mathrm{mL}^{-1}}{\mathrm{C} 5 \mathrm{a}}$ \\
\hline \multicolumn{7}{|l|}{ CLRTI } \\
\hline $\operatorname{ELF}(\mathrm{n}=10)$ & $50.3 \pm 11.3^{+} * *$ & $0.11 \pm 0.06$ & $6.17 \pm 1.23 * *$ & $103.9 \pm 34.2 *$ & $3.95 \pm 1.21^{*}$ & $332 \pm 146$ \\
\hline Plasma $(\mathrm{n}=8)$ & $<0.05$ & $0.018 \pm 0.012$ & $<0.01$ & $0.34 \pm 0.07$ & $0.053 \pm 0.008$ & $18.0 \pm 4.7$ \\
\hline \multicolumn{7}{|l|}{ Control } \\
\hline ELF $(n=3)$ & $<0.05$ & $<0.005$ & $1.66 \pm 0.29$ & $<0.03$ & $0.61 \pm 0.08$ & $210 \pm 43$ \\
\hline Plasma $(n=3)$ & $<0.05$ & $<0.005$ & $0.016 \pm 0.002$ & $0.15 \pm 0.02$ & $0.053 \pm 0.008$ & $22.0 \pm 0.6$ \\
\hline
\end{tabular}

Values are presented as mean \pm SEM. IL: interleukin; TNF- $\alpha$ : tumour necrosis factor- $\alpha$; NE: neutrophil elastase; LTB $_{4}:$ leukotriene $\mathrm{B}_{4}{ }^{+}$: $\mathrm{p}<0.05$, compared with ELF concentrations in control subjects; *: $\mathrm{p}<0.05 ; * *: \mathrm{p}<0.01$, compared with plasma concentrations in CLRTI. 
Table 7. - Roxithromycin concentrations in plasma, epithelial lining fluid (ELF), and bronchoalveolar lavage (BAL) cells from patients with chronic lower respiratory tract infections after three months of treatment

\begin{tabular}{|c|c|c|c|c|c|c|}
\hline Case & $\begin{array}{l}\text { Plasma } \\
\mu \mathrm{g} \cdot \mathrm{mL}^{-1}\end{array}$ & $\begin{array}{l}\text { BAL fluid } \\
\mu \mathrm{g} \cdot \mathrm{mL}^{-1}\end{array}$ & $\begin{array}{l}\text { Calculated } \\
\text { ELF } \\
\mu \mathrm{g} \cdot \mathrm{mL}^{-1}\end{array}$ & $\begin{array}{l}\text { BAL cell } \\
\text { lysate } \\
\mu \mathrm{g} \cdot \mathrm{mL}^{-1}\end{array}$ & $\begin{array}{l}\text { AM count in } \\
\text { BAL cell lysate } \\
\quad \times 10^{5} \cdot \mathrm{mL}^{-1}\end{array}$ & $\begin{array}{l}\text { Calculated } \\
\text { BAL cell } \\
\mu \mathrm{g} \cdot \mathrm{mL}^{-1}\end{array}$ \\
\hline 1 & 4.29 & $<0.05$ & $<0.41$ & ND & ND & ND \\
\hline 2 & 2.55 & 0.10 & 1.56 & ND & ND & ND \\
\hline 3 & 4.27 & $<0.05$ & $<2.67$ & $<0.05$ & 2.05 & $<97.8$ \\
\hline 4 & 8.78 & 0.11 & 4.77 & 0.64 & 3.06 & 840 \\
\hline 7 & 1.94 & $<0.05$ & $<1.13$ & 0.56 & 2.63 & 855 \\
\hline 9 & ND & $<0.05$ & $<1.41$ & 2.63 & 11.04 & 956 \\
\hline 10 & 0.59 & $<0.05$ & $<2.07$ & 4.72 & 9.49 & 1967 \\
\hline Mean \pm SEM & $3.74 \pm 1.16$ & $0.03 \pm 0.02^{\dagger}$ & $0.90 \pm 0.68^{\dagger}$ & $1.71 \pm 0.88^{\dagger}$ & $5.65 \pm 1.91$ & $924 \pm 313^{\dagger}, * * *$ \\
\hline
\end{tabular}

AM: alveolar macrophage; ND: not done. ${ }^{\dagger}$ : calculated including the data below detection limit as 0 ; $* * *:$ p<0.001, compared with plasma and ELF concentrations.

\section{Discussion}

RXM significantly improved the clinical symptoms of CLRTI patients despite its failure to eliminate airway bacteria. It has been demonstrated in this study that various chemotactic mediators including IL-8, NE, and C5a contribute to the airway inflammation of CLRTI patients. The clinical improvement after the RXM treatment was associated with a decrease in IL-8, NE, and $\mathrm{LTB}_{4}$ concentrations in ELF and the resulting attenuation of neutrophilic inflammation. A marked RXM accumulation in BAL cells was demonstrated in vivo and the inhibitory effects of RXM on the release of pro-inflammatory cytokines were observed in vitro. These findings support the hypothesis that long-term administration of RXM leads to decreased chemotactic mediator release from inflammatory cells in the airways of CLRTI patients, which may in part account for the clinical efficacy of RXM.

IL-8 was considered to play a primary role in neutrophilic inflammation in the airways of CLRTI patients on the basis of the comparison between the patients and control subjects, before and after the treatment, and the relationship to the ELF neutrophil counts. Although the major IL-8 producing cells in the airways of CLRTI patients were undetermined, AM, neutrophils and epithelial cells can produce IL-8 [13, 18, 23]. NE contributes to the neutrophilic inflammation as it correlated with the ELF neutrophil counts and decreased after treatment with RXM. NE levels also paralleled IL-8 levels. Previous reports suggest that NE is released from neutrophils activated by IL- 8 [24] and induces IL- 8 expression in epithelial cells [15]. It was also reported that activated neutrophils produce $\mathrm{LTB}_{4}[25]$, and that $\mathrm{LTB}_{4}$ upregulates neutrophil-derived IL-8 [14]. LTB 4 levels in ELF from CLRTI patients were increased compared with those in plasma, but did not significantly correlate with neutrophil counts or IL- 8 in the present study. These results suggest that neutrophils may not be a primary source of $\mathrm{LTB}_{4}$ in the airways of CLRTI patients. Since LTB decreased after treatment with RXM, the effects of RXM may be at least partly mediated by a decrease in $\mathrm{LTB}_{4}$ levels. IL-1 $\beta$ correlated with IL-8 and NE levels in ELF but not with neutrophil counts. The ELF IL-1 $\beta$ levels were not higher in CLRTI patients compared to control subjects, and did not fall after RXM treatment. C5a concentrations correlated well with neutrophil counts and
NE levels in ELF, but the ELF C5a levels in CLRTI patients were similar to those in control subjects. Furthermore, they did not decrease after RXM treatment, and did not correlate with IL-8. Therefore, RXM effects may not be mediated by a decrease in C5a levels. It is unlikely that TNF- $\alpha$ plays important roles in the pathogenesis of CLRTI as its ELF levels were much lower than other mediators and did not change after treatment with RXM.

The effects of RXM on clinical symptoms, pulmonary functions and chest radiographic findings in CLRTI patients were remarkable. Clinical symptoms and chest radiographic findings were improved in all CLRTI patients studied based on the author's scoring criteria, but the percentage of improvement varied in each patient. There was no significant difference in the improvement of these scores between DPB and BE. Further investigations will be required to elucidate the factors determining the response of CLRTI patients to macrolide antibiotic therapy, including chest radiographic findings, infected bacteria, pulmonary function, etc. However, these results suggested that improvement in clinical and chest radiographic findings paralleled the decreased neutrophil accumulation in the airspaces, but was not always accompanied by a decrease in the number of airway bacteria. Although clinical findings paralleled decreases in the amount of bacteria in $30 \%$ of patients, they were improved despite an increased or unchanged number of bacteria in $50 \%$ of patients. The uncontrolled production of neutrophil chemotactic mediators, including IL-8, by inflammatory cells may play major roles in recruiting neutrophils to the airways and may exacerbate respiratory symptoms, especially in DPB patients. Decreased ELF levels of IL-8, NE and $\mathrm{LTB}_{4}$ after the RXM treatment suggest that RXM could inhibit the excess release of these mediators from inflammatory cells in vivo, which was supported by the inhibitory effects of RXM on the release of IL- 8 from AM and neutrophils in vitro. Although the in vitro RXM effects were significant only at a high concentration, RXM was markedly concentrated in AM after 3 months of administration. In addition, the in vivo results demonstrated that a decrease in IL-8 levels can lead to a decrease in other chemotactic mediators including NE and IL-1 $\beta$, which may efficiently attenuate neutrophilic inflammation in the airways. Therefore, RXM may actually inhibit the release of IL-8 and improve neutrophilic inflammation in vivo. Previous reports also suggest that macrolide antibiotics can 

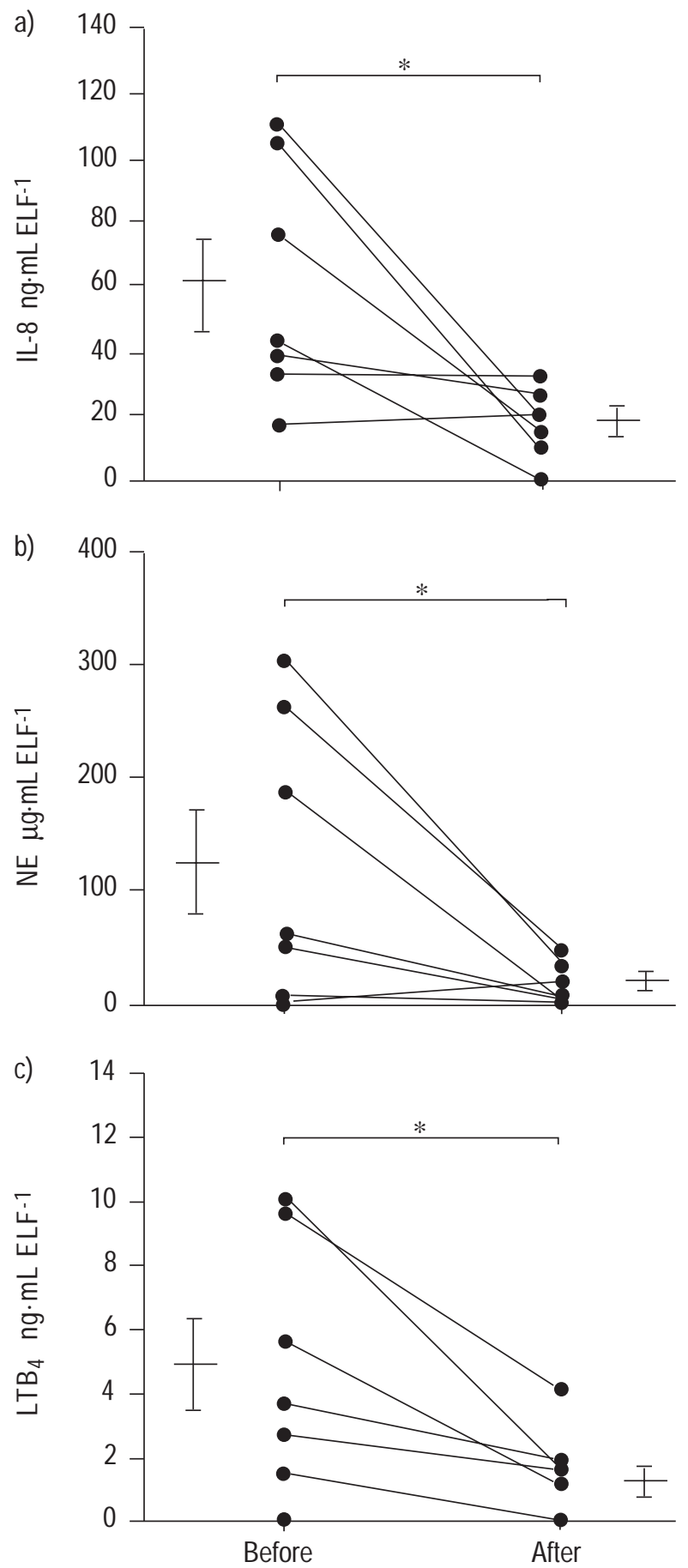

Fig. 1. - a) Interleukin (IL)-8 levels in epithelial lining fluid (ELF) before and after treatment with roxithromycin (RXM). The levels were significantly decreased after treatment. b) Neutrophil elastase (NE) concentrations in ELF before and after treatment with RXM, which were significantly decreased after treatment. c) Leukotriene $\mathrm{B}_{4}\left(\mathrm{LTB}_{4}\right)$ concentrations in ELF before and after treatment with RXM, which were significantly decreased after treatment. *: $\mathrm{p}<0.05$.

accumulate within phagocytes to higher levels than the other antibiotics, and that this process is more pronounced for RXM than for erythromycin (EM) [26-29]. These results may partly explain the unique effects of macrolide antibiotics on CLRTI patients, and suggest a potential superior action of RXM over EM.
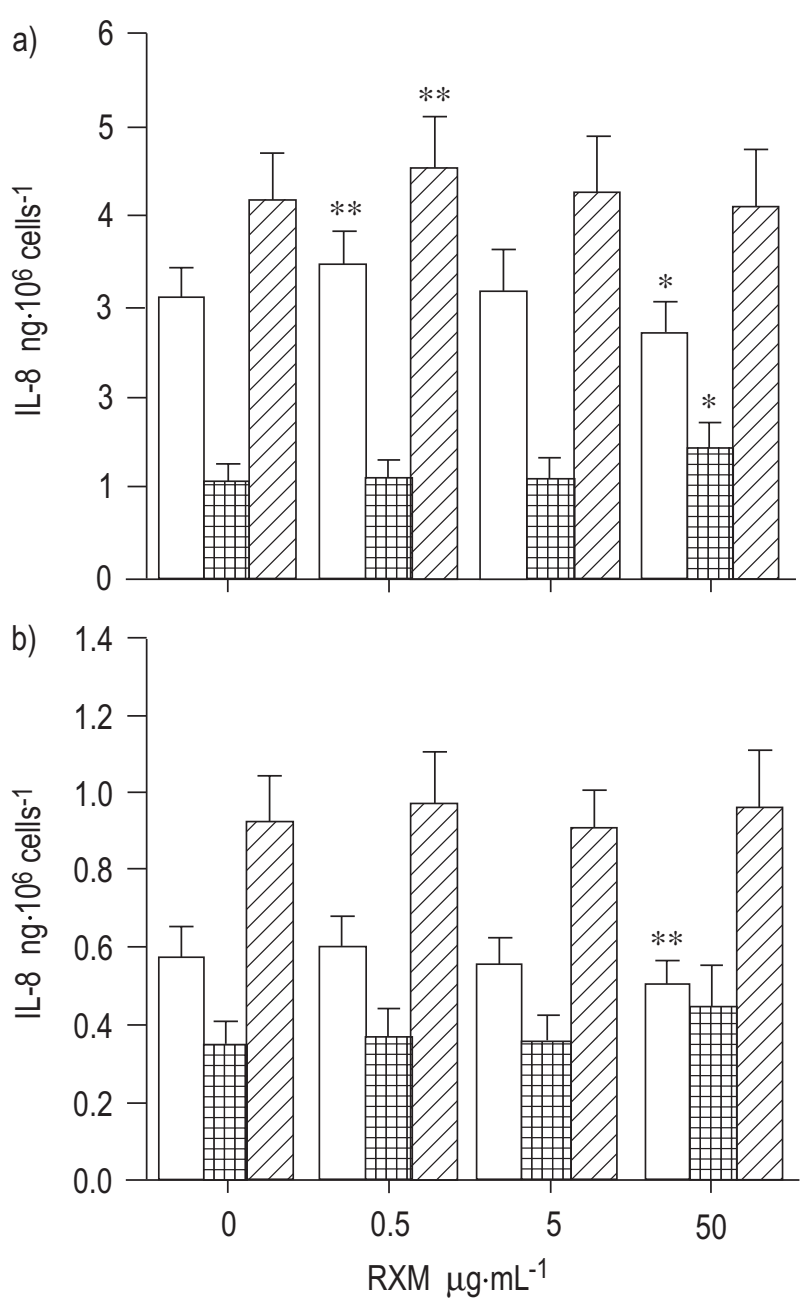

Fig. 2. - Effects of roxithromycin (RXM) on interleukin (IL)-8 production and release from a) alveolar macrophages (AM) $(n=4)$ and $b)$ neutrophils $(\mathrm{n}=7)$. a) The low concentration of RXM $\left(0.5 \mu \mathrm{g} \cdot \mathrm{mL}^{-1}\right)$ led to an increase in the extracellular and total IL-8 from AM. In contrast, a high concentration of RXM $\left(50 \mu \mathrm{g} \cdot \mathrm{mL}^{-1}\right)$ decreased extracellular IL-8 and increased cell-associated IL-8 in AM. b) Extracellular IL-8 was decreased when neutrophils were preincubated with $50 \mu \mathrm{g} \cdot \mathrm{mL}^{-1}$ of RXM, but there was no significant change in the IL-8 levels in neutrophils preincubated with $0.5 \mu \mathrm{g} \cdot \mathrm{mL}^{-1}$ of RXM. $\square$ : extracellular; 曲: cellassociated; $\mathbb{Z}$ : total. ${ }^{*}$ : $\mathrm{p}<0.05 ;{ }^{* *}$ : $\mathrm{p}<0.01$, compared with value without RXM, paired Student's t-test.

In addition to the inhibitory effects on IL-8 release, various immunoregulatory effects have been reported for macrolide antibiotics. These effects include inhibition of neutrophil chemotaxis [5] and superoxide production [6], resolution of biofilms surrounding bacteria [30], activation of cilial movement [31] and a decrease in mucus secretion [32]. The clinical efficacy of macrolides may be a consequence of all these actions. Since the attenuation of chemotaxis and activation of activated neutrophils by macrolides is distinct among these mechanisms, macrolides may be applicable to other neutrophil-mediated pulmonary disorders, such as cystic fibrosis, adult respiratory distress syndrome and subacutely exacerbating idiopathic pulmonary fibrosis $[4,5,18,33]$.

RXM has a longer plasma half-life than EM [16]. Sufficient plasma concentrations can be obtained when a 150 $\mathrm{mg}$ tablet is administered twice a day, which is equivalent 

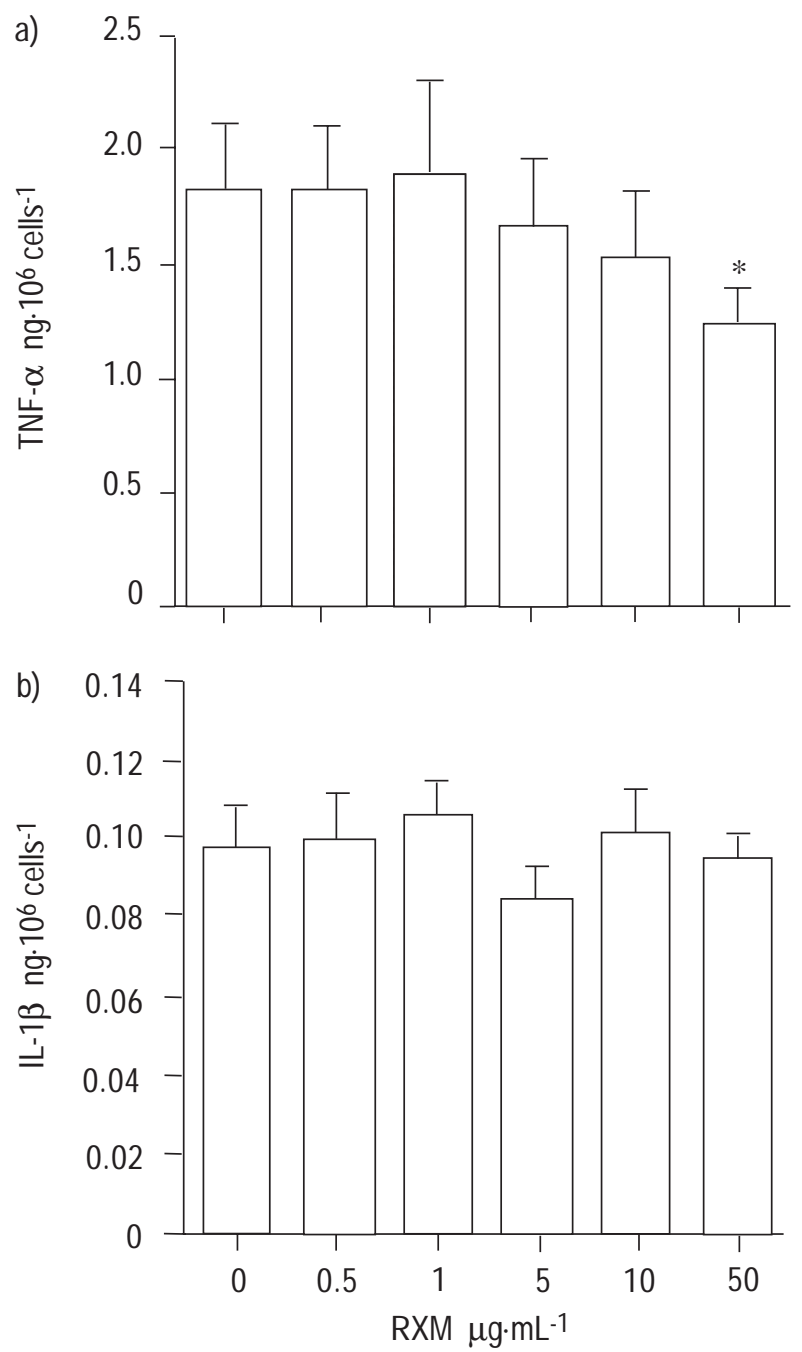

Fig. 3. - Effects of roxithromycin (RXM) on the release of tumour necrosis factor (TNF)- $\alpha$ (a) and interleukin (IL)-1 $\beta$ (b) from alveolar macrophages (AM) $(n=4)$. a) The high concentration of RXM (50 $\mu \mathrm{g} \cdot \mathrm{mL}^{-1}$ ) significantly decreased the extracellular release of TNF- $\alpha$ from AM. *: p<0.05, compared with value without RXM, paired Student's t-test. b) RXM did not affect the extracellular release of IL-1 $\beta$.

to $1,200 \mathrm{mg}$ daily of EM [34]. In contrast, low-dose EM (200-600 mg daily) has been regularly administered to CLRTI patients [1-3] and the major reason for the low dose is to avoid the adverse effects of EM. Although a standard dose $\left(300 \mathrm{mg} \cdot \mathrm{day}^{-1}\right)$ of RXM was given for 3 months in this study, no patient showed any signs or symptoms of adverse effects. The clinical signs and symptoms of the treated patients were markedly improved within 3 months, and the clinical efficacy was observed within 4 weeks after commencement of RXM treatment in most patients. However, it is unclear how long this improvement will continue after the discontinuation of RXM. The optimal duration of the treatment has not been determined, but oral macrolide therapy is often continued over several years in Japan. The duration of the treatment is currently optimized according to the clinical course of an individual patient. The authors reduced the RXM dose to $150 \mathrm{mg} \cdot$ day $^{-1}$ after the three month treatment with 300 $\mathrm{mg}$ of RXM. If the clinical efficacy is due to the intracellularly accumulated RXM in AM, neutrophilic inflam- mation could recur after the discontinuation of RXM. Longer observation is necessary to establish a standard protocol for the treatment of CLRTI patients with macrolide antibiotics.

In summary, high levels of the chemotactic mediators interleukin-8, neutrophil elastase and leukotriene $B_{4}$ exist in the airway of chronic lower respiratory tract infection patients. Treatment with roxithromycin resulted in a remarkable clinical improvement, which is associated with decreased levels of these mediators. In combination with the results of in vitro experiments, it is speculated that the clinical efficacy may be mediated by the inhibitory effects of intracellularly accumulated roxithromycin on the excess release of chemotactic mediators, especially interleukin-8, from inflammatory cells.

Acknowledgements. The authors thank T. Kawashiro (National Higashi-Saitama Hospital) and M. Sato (Eisai Co., Ltd.) for their invaluable assistance.

\section{References}

1. Ichikawa $\mathrm{Y}$, Nimomiya $\mathrm{H}, \mathrm{Koga} \mathrm{H}$, et al. Erythromycin reduces neutrophils and neutrophil derived elastolyticlike activity in the lower respiratory tract of bronchiolitis patients. Am Rev Respir Dis 1992; 146: 196-203.

2. Kadota J, Sakito O, Kohno S, et al. A mechanism of erythromycin treatment in patients with diffuse panbronchiolitis. Am Rev Respir Dis 1993; 147: 153-159.

3. Nagai H, Shishido H, Yoneda R, Yamaguchi E, Tamura A, Kurashima A. Long-term low dose administration of erythromycin to patients with diffuse panbronchiolitis. Respiration 1991; 58: 145-149.

4. Fitzgerald JE, King TE Jr, Lynch DA, Tuder RM, Schwarz MI. Diffuse panbronchiolitis in the United States. Am J Respir Crit Care Med 1996; 154: 497-503.

5. Oda H, Kadota J, Kohno S, Hara K. Erythromycin inhibits neutrophil chemotaxis in bronchoalveoli of diffuse panbronchiolitis. Chest 1994; 106: 1116-1123.

6. Umeki S. Anti-inflammatory action of erythromycin: its inhibitory effect on neutrophil NADPH oxidase activity. Chest 1993; 104: 1191-1193.

7. Oishi K, Sonoda F, Kobayashi S, et al. Role of interleukin-8 (IL-8) and an inhibitory effect of erythromycin on IL-8 release in the airways of patients with chronic airway diseases. Infect Immun 1994; 62: 4145-4152.

8. $\mathrm{O}^{\prime}$ Connor CM, Gaffney K, Keane J, et al. $\alpha_{1}$-proteinase inhibitor, elastase activity, and lung disease severity in cystic fibrosis. Am Rev Respir Dis 1993; 148: 1665-1670.

9. Konstan MW, Walenga RW, Hilliard KA, Hilliard JB. Leukotriene $\mathrm{B}_{4}$ markedly elevated in the epithelial lining fluid of patients with cystic fibrosis. Am Rev Respir Dis 1993; 148: 896-901.

10. Sakito O, Kadota J, Kohno S, Abe K, Shirai R, Hara K. Interleukin $1 \beta$, tumor necrosis factor alpha, and interleukin 8 in bronchoalveolar lavage fluid of patients with diffuse panbronchiolitis: a potential mechanism of macrolide therapy. Respiration 1996; 63: 42-48.

11. Matsushima K, Morishita K, Yoshimura T, et al. Molecular cloning of a human monocyte-derived neutrophil chemotactic factor (MDNCF) and the induction of MDNCF mRNA by interleukin 1 and tumor necrosis factor. $J$ Exp Med 1988; 167: 1883-1893.

12. Elner VM, Strieter RM, Elner SG, Baggiolini M, Lindley I, Kunkel SL. Neutrophil chemotactic factor (IL-8) gene 
expression by cytokine-treated retinal pigment epithelial cells. Am J Pathol 1990; 136: 745-750.

13. Fujishima $\mathrm{S}$, Hoffman $\mathrm{AR}, \mathrm{Vu} \mathrm{T}$, et al. Regulation of neutrophil interleukin-8 gene expression and protein secretion by LPS, TNF $\alpha$, and IL-1 1 . J Cell Physiol 1993; 154: 478-485.

14. McCain RW, Holden EP, Blackwell TR, Christman JW. Leukotriene $\mathrm{B}_{4}$ stimulates human polymorphonuclear leukocytes to synthesize and release interleukin-8 in vitro. Am J Respir Cell Mol Biol 1994; 10: 651-657.

15. Nakamura H, Yoshimura K, McElvaney NG, Crystal RG. Neutrophil elastase in respiratory epithelial lining fluid of individuals with cystic fibrosis induces interleukin-8 gene expression in a human bronchial epithelial cell line. J Clin Invest 1992; 89: 1478-1484.

16. Konno S, Adachi M, Asano K, Kawazoe T, Okamoto K, Takahashi T. Influences of roxithromycin on cell-mediated immune responses. Life Sci 1992; 51: 107-112.

17. The BAL Cooperative Group Steering Comittee. Bronchoalveolar lavage constituents in healthy individuals, idiopathic pulmonary fibrosis, and selected comparison groups. Am Rev Respir Dis 1990; 141: 169-202.

18. Nakamura H, Fujishima S, Waki Y, et al. Priming of alveolar macrophages for interleukin-8 production in patients with idiopathic pulmonary fibrosis. Am J Respir Crit Care Med 1995; 152: 1579-1586.

19. Rennard SI, Basset G, Lecossier D, et al. Estimation of volume of epithelial lining fluid recovered by lavage using urea as marker of dilution. $J$ Appl Physiol 1986; 60: 532-538.

20. Poupard JA, Dewees LB, Morton HE. Antibiotic susceptibility of Klebsiella enterobacter as determined by a single high-concentration disc method. Antimicrob Agents Chemother 1969; 9: 489-494.

21. Munoz C, Misset B, Fitting C, Bleriot JP, Carlet J, Cavaillon JM. Dissociation between plasma and monocyteassociated cytokines during sepsis. Eur J Immunol 1991; 21: 2177-2184.

22. Crapo JD, Barry BE, Gehr P, Bachofen M, Weibel ER. Cell number and cell characteristics of the normal human lung. Am Rev Respir Dis 1982; 125: 332-337.

23. Nakamura H, Yoshimura K, Jaffe HA, Crystal RG. Interleukin-8 gene expression in human bronchial epithelial cells. J Biol Chem 1991; 266: 19611-19617.
24. Thelen M, Peveri P, Kemen P, Von Tscarner V, Waltz A, Baggiolini M. Mechanism of neutrophil activation by NAF, a novel monocyte-derived peptide agonist. FASEB J 1988; 2: 2702-2706.

25. Ford-Hutchinson AW, Bray MA, Doig MV, Shipley ME, Smith MJH. Leukotriene $\mathrm{B}_{4}$, potent chemokinetic and aggregating substance released from polymorphonuclear leukocytes. Nature 1980; 286: 264-265.

26. Hand WL, King-Thompson NL. Contrasts between phagocyte antibiotic uptake and subsequent intracellular bactericidal activity. Antimicrob Agents Chemother 1986; 29 : 135-140.

27. Stamler DA, Edelstein MAC, Edelstein PH. Azithromycin pharmacokinetics and intracellular concentrations in Legionella pneumophila-infected and uninfected guinea pigs and their alveolar macrophages. Antimicrob Agents Chemother 1994; 38: 217-222.

28. Hand WL, King-Thompson N, Holman JW. Entry of roxithromycin (RU 965), imipenem, cefotaxime, trimethoprim, and metronidazole into human polymorphonuclear leukocytes. Antimicrob Agents Chemother 1987; 31: $1553-1557$.

29. Carlier M, Zenebergh A, Tulkens PM. Cellular uptake and subcellular distribution of roxithromycin and erythromycin in phagocytic cells. $J$ Antimicrobial Chemotherapy 1987; 20: 47-56.

30. Yasuda H, Ajiki Y, Koga T, Kawada H, Yokota T. Interaction between biofilms formed by Pseudomonas aeruginosa and clarithromycin. Antimicrob Agents Chemother 1993; 37: 1749-1755.

31. Takeyama K, Tamaoki J, Chiyotani A, Tagaya E, Konno $\mathrm{K}$. Effect of macrolide antibiotics on ciliary motility in rabbit airway epithelium in vitro. J Pharm Pharmacol 1993; 45: 756-758.

32. Tamaoki J, Isono K, Sakai N, Kanemura T, Konno K. Erythromycin inhibits $\mathrm{Cl}$ secretion across canine tracheal epithelial cells. Eur Respir J 1992; 5: 234-238.

33. Fujishima S, Sasaki J, Shinozawa Y, Takuma K, Hori S, Aikawa N. Interleukin 8 in ARDS. Lancet 1993; 342: 237-238.

34. Konno S, Asano K, Kurokawa M, Ikeda K, Okamoto K, Adachi M. Antiasthmatic activity of a macrolide antibiotic, roxithromycin: analysis of possible mechanisms in vitro and in vivo. Int Arch Allergy Immunol 1994; 105: 308-316. 